\title{
Blood pressure predictors of stroke in rural Chinese dwellers with hypertension: a large-scale prospective cohort study
}

\author{
Jia Zheng ${ }^{1}$, Zhaoqing Sun ${ }^{2}$, Xiaofan Guo ${ }^{3}$, Yanxia Xie ${ }^{1}$, Yingxian Sun ${ }^{2^{*}}$ and Liqiang Zheng ${ }^{1 *}$ (D)
}

\begin{abstract}
Background: Little was known about the different predictive power of blood pressure (BP) parameters (SBP, systolic BP; mean arterial pressure, MAP; pulse pressure, PP; and diastolic BP, DBP) and stroke incidence. This study's aim was to compare power of BP parameters predict stroke events among rural dwelling Chinese individuals with hypertension.
\end{abstract}

Method: A total of 5097 hypertension patients (56.2\% women; mean age, $56.3 \pm 11.2$ years) were included in the prospective cohort study with a median follow-up of 8.4 years.

Results: Until the end of the last follow-up, there were 501 onset strokes (310 ischemic, 186 hemorrhagic, and 5 unclassified strokes) among the 5097 participants. The results showed that hazard ratio (HR) (95\% confidence interval, 95\% Cl) with an increment of $5 \mathrm{mmHg}$ were 1.095 (1.070-1.121) for PP, 1.173 (1.139-1.208) for MAP, 1.109(1.089-1.130) for SBP, 1.143(1.104-1.185) for DBP. The SBP indicated the largest $\beta$ coefficient in the Cox proportional hazard model for all stroke except PP or MAP, and the SBP revealed slightly higher value than MAP $\left(\beta_{\mathrm{SBP}}=0.435, \beta_{\mathrm{MAP}}=0.430, P=0.756\right)$.

Conclusions: Both PP and MAP were predictive factors for stroke. The MAP showed a stronger ability to predict stroke events than PP, and slightly inferior to SBP for hypertension patients.

Keywords: Blood pressure, Stroke, Hypertension

\section{Background}

Stroke is considered to be the second primary cause of death in the world [1], and China has the highest burden of stroke in the glob [2]. In addition, hypertension is considered to be the mainly risk factor of disability-adjusted lifeyears and deaths [3]. Previous study has indicated that over one-quarter of adult population were hypertension patients in China [4]. For hypertension patients, the incidence of stroke is higher than it in persons with normal BP [5].

Recently, MAP and PP have been used as predictors for stroke events and confirmed in many studies [6-21]. MAP is another measure of the overall circulating pressure load

\footnotetext{
*Correspondence: sunyingxian12@126.com; liqiangzheng@126.com 2Department of Cardiology, Shengjing Hospital of China Medical University, Shenyang 110004, People's Republic of China

'Department of Clinical Epidemiology, Library, Department of Health Policy and Hospital Management, Shengjing Hospital of China Medical University, Shenyang 110004, People's Republic of China

Full list of author information is available at the end of the article
}

and considered to predict adverse cardiovascular outcomes. The value of MAP can be directly determined by cardiac catheterization or estimated by a formula [e.g., diastolic + $1 / 3 \times$ (systolic-diastolic)]. However, as the age of the patient increases, the discrimination ability of the mean arterial pressure decreases. DBP peaked at the age of 55 and then decreased, while the systolic blood pressure (SBP) continued to grow with age, and higher every 10 years [22]. Thus, based on the individual changes in SBP and DBP with age, actual changes in MAP tend to be low with age. At the same time, there is increasing emphasis on SBP as the effective indicator of cardiovascular disease (CVD) apart from other BP parameters for the middle-aged and elderly person. The correlation between PP and SBP is more closely related to DBP with an increasing age. The PP is regarded as a proper predictor of CVD in the general population. Nevertheless, few researches have been conducted among hypertensive patients, especially in Chinese [6-9, 23]. It is

(c) The Author(s). 2019 Open Access This article is distributed under the terms of the Creative Commons Attribution 4.0 International License (http://creativecommons.org/licenses/by/4.0/), which permits unrestricted use, distribution, and 
particularly crucial to discover a strong predictive indicator of stroke in this group, since there were some limitations in previous studies, such as short follow-up time [23], risk factors for stroke adjusted inadequately, or lack of comparisons of HR values among the four BP parameters (PP, DBP, MAP, and SBP) [6-10].

The goal of our study was to explored the relationship between infrequent BP parameters (PP and MAP) and stroke events [All stroke, ischemic stroke (IS), hemorrhage stroke $(\mathrm{HS})]$ in prospective hypertension cohort and compare the predictive values of four BP parameters for stroke events.

\section{Methods}

\section{Study population}

The China Medical University Ethics Committee had approved the study plan and received the written informed consent from all patients or their guardians.

Our data comes from a prospective cohort from Fuxin county hypertensive population. The first multistage cluster random sampling design was conducted in 64 rural communities in Fuxin county (including seven cities in five locations: east, west, south, north and central) of Liaoning province, China. Hypertensive patients aged $\geq 35$ years who agreed to take part in the study and signed informed consent forms were included. At the same time, pregnant women, those having malignant tumors, severe hepatic and renal insufficiency, those unwilling to participate in the study were excluded. 6412 hypertensive patients were covered at the start of our study [24, 25]. All the eligible participants were invited to the following visits. And the three follow-up visits as detailed previously [24]. The detailed inclusion process of participants is shown in Fig. 1.

\section{Study outcomes}

Our study endpoint was stroke, according to the MONICA criteria to confirmed the events. The event with the major events in the etiology of blood vessels, including local or global brain disease lasting for more than $24 \mathrm{~h}$, and stroke events due to death or surgical duration less than $24 \mathrm{~h}$ [25]. The project diagnostic team confirmed the new stroke events during follow-up visits and the final verification approved. Data classification and measurement on stroke as detailed previously [24].

\section{BP measurement}

Standardized measurement of BP values have been detailed in previous articles [24]. We defined hypertension as the take of anti-hypertensive medications in the last 2 weeks or DBP $\geq 90 \mathrm{mmHg}$ or $\mathrm{SBP} \geq 140 \mathrm{mmHg}$. Further calculations of BP parameters were included such as: $P P=S B P-D B P ; M A P=(2 \times D B P+S B P) / 3$.

\section{Other risk factors}

Information on other risk factors data (serum glucose, lipids, cholesterol) collection and measurement had been

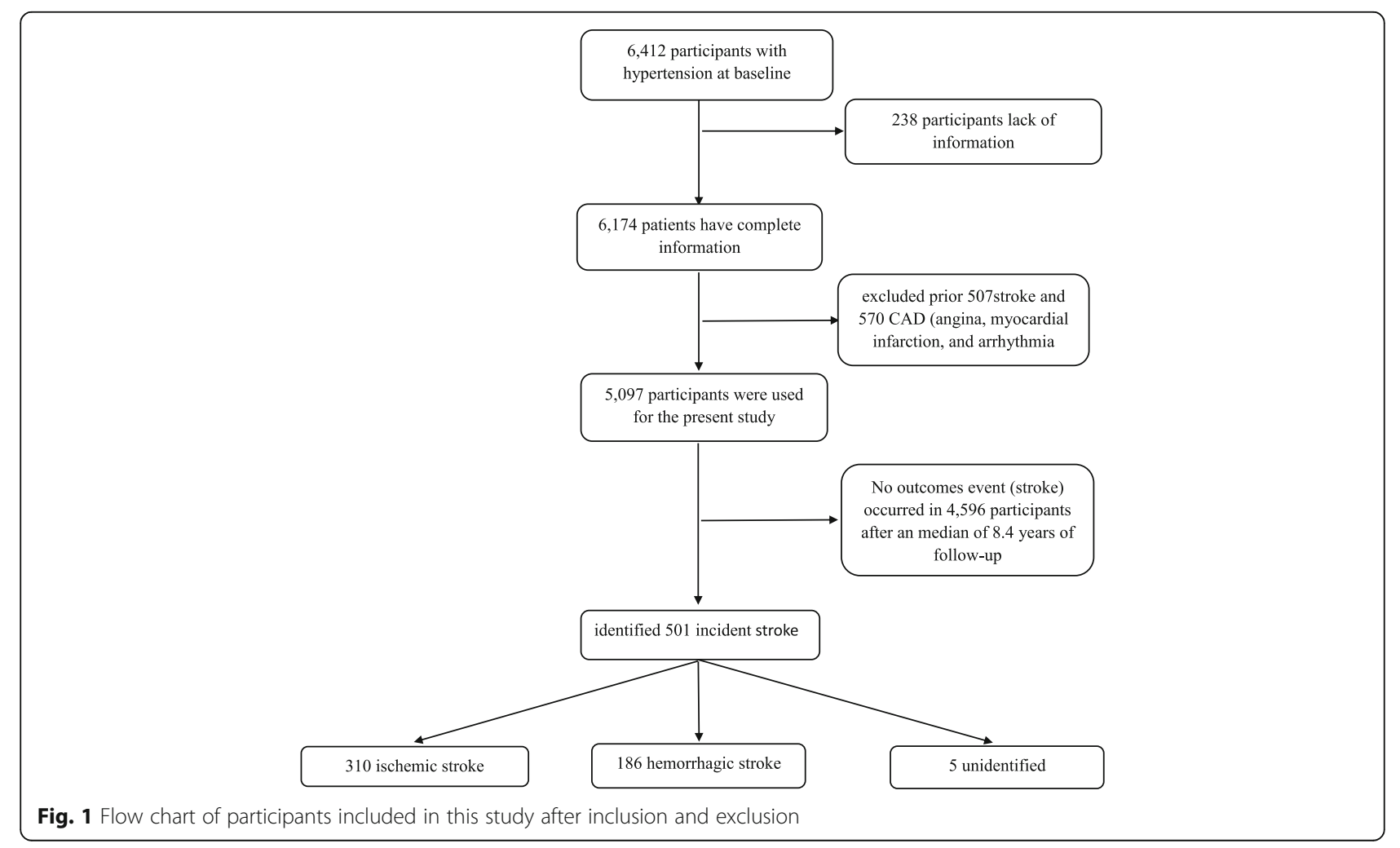


described in previously literature $[23,24,26]$. Professional physicians performed face-to-face interviews with patients to obtain lifestyle factors (smoking, drinking, and BP medication). The smoking and drinking were defined as detailed previously [11, 24]. We defined diabetes as current treatment with oral hypoglycemic agents or insulin or fasting serum glucose levels $\geq 7.0 \mathrm{mmol} / \mathrm{l}$.

\section{Statistical analysis}

The Pearson correlation was applied to assess the correlation coefficient among BP parameters. The Cox proportional hazard model was applied to count the HR value and 95\% CI of four BP parameters for the risk of incident stroke. First, four BP parameters in form of continuous variables in the model, and the HRs were calculated with $1 \mathrm{SD}$ $\mathrm{mmHg}$ intervals to estimate the relationships among four $\mathrm{BP}$ parameters and onset stroke events. The incident stroke was examined to determine the association with four BP values across the age $<60$ years and the age of $\geq 60$ years. Multivariable model was adjusted by sex, ethnicity, age, body mass index (BMI), smoking, diabetes mellitus (DM), drinking, heart rate (HR), TC, LDL-C, TG, HDL-C, and anti-hypertensive medications. Principle of comparing the difference in HR values were described in the previous published literature [24]. We used SPSS 22.0 (IBM Inc.,
Chicago, IL, USA) to conducted data analysis and $P<0.05$ was regarded to be significant.

\section{Results}

Baseline information in this study were showed in Table 1. Baseline mean (SD) age of women was 56.3 (11.2) years of the 5097 initially no-stroke hypertensive patients. A positive correlation between PP and SBP $(r=$ 0.826; $P<0.001$ ) was found, but $\mathrm{PP}$ revealed negative correlations with DBP $(\mathrm{r}=-0.158 ; P<0.001)$ and MAP $(r=0.357 ; P<0.001)$ as can be shown in Fig. 2 .

501 onset outcomes occurred until the last follow-up visit(310 IS events, 186 HS events, and 5 unclassified stroke events). The incidence density of all strokes were 1236.30 per 100,000 person-years (95\% CI: 1167.811304.79), IS was 764.97 (95\% CI: 710.97-818.97), and HS was 458.99 (95\% CI: 417.10-500.89). HRs (95\% CI) of future stroke after multivariate adjustment for each $\mathrm{BP}$ parameters increased by $1 \mathrm{SD} \mathrm{mmHg}$ were listed in Table 2. All the BP parameters (All stroke, IS, and HS) showed significant association with the risk of stroke incident at 0.001 level.

Table 3 demonstrates the adjusted HRs of BP parameters that had been standardized in the Cox proportional hazard model for stroke according to age categories. The

Table 1 Baseline Characteristics of hypertensive patients

\begin{tabular}{|c|c|c|c|}
\hline Variables & strokes & non-strokes & $P$-value \\
\hline $\mathrm{n}$ & 4596 & 501 & \\
\hline Age, years, Mean (SD) & $55.8(11.18)$ & $60.4(10.99)$ & \\
\hline Women, n (\%) & $2653(57.7)$ & $213(42.5)$ & $<0.001$ \\
\hline Han ethnicity, n (\%) & $3691(80.3)$ & $386(77.0)$ & 0.835 \\
\hline BMl, kg/m2,Mean (SD) & 23.9(3.41) & $23.5(3.25)$ & 0.011 \\
\hline Current smoking, n (\%) & 1802(39.2) & $243(48.5)$ & $<0.001$ \\
\hline Current drinking, n (\%) & 1334(29.0) & 169(33.7) & 0.028 \\
\hline Taking anti-hypertensive drugs, n (\%) & 1004(21.8) & 187(37.3) & $<0.001$ \\
\hline HR, beats/min, Mean (SD) & $76.0(11.10)$ & $75.6(11.32)$ & 0.505 \\
\hline Diabetes mellitus, n (\%) & $349(7.6)$ & $52(10.4)$ & 0.028 \\
\hline \multicolumn{4}{|l|}{ Lipid,mmol/L, Median (IQR) } \\
\hline TC & $5.16(4.52-5.82)$ & $5.33(4.61-6.01)$ & 0.002 \\
\hline TG & $1.31(0.93-1.97)$ & $1.38(0.98-2.09)$ & 0.091 \\
\hline $\mathrm{HDL}-\mathrm{C}$ & $1.40(1.20-1.62)$ & $1.42(1.20-1.64)$ & 0.543 \\
\hline LDL-C & $2.72(2.27-3.20)$ & $2.88(2.37-3.34)$ & 0.001 \\
\hline \multicolumn{4}{|l|}{ BP Parameters, mmHg, Mean (SD) } \\
\hline SBP & 158.4(20.51) & $172.0(21.77)$ & $<0.001$ \\
\hline DBP & $93.6(11.69)$ & $97.5(14.00)$ & $<0.001$ \\
\hline MAP & 136.8(15.65) & $147.2(17.47)$ & $<0.001$ \\
\hline PP & 64.8(19.11) & $74.5(18.49)$ & $<0.001$ \\
\hline
\end{tabular}

The body mass index (BMI) is the weight in kilograms divided by the square of the height in meters. BP blood pressure, HR heart rate, BMI body mass index, IQR inter-quartile range, TC Total cholesterol, TG Triglycerides, HDL-C high-density lipoprotein cholesterol, LDL-C low-density lipoprotein cholesterol, SBP systolic blood pressure, $D B P$ diastolic blood pressure, $P P$ pulse pressure, MAP mean arterial pressure 

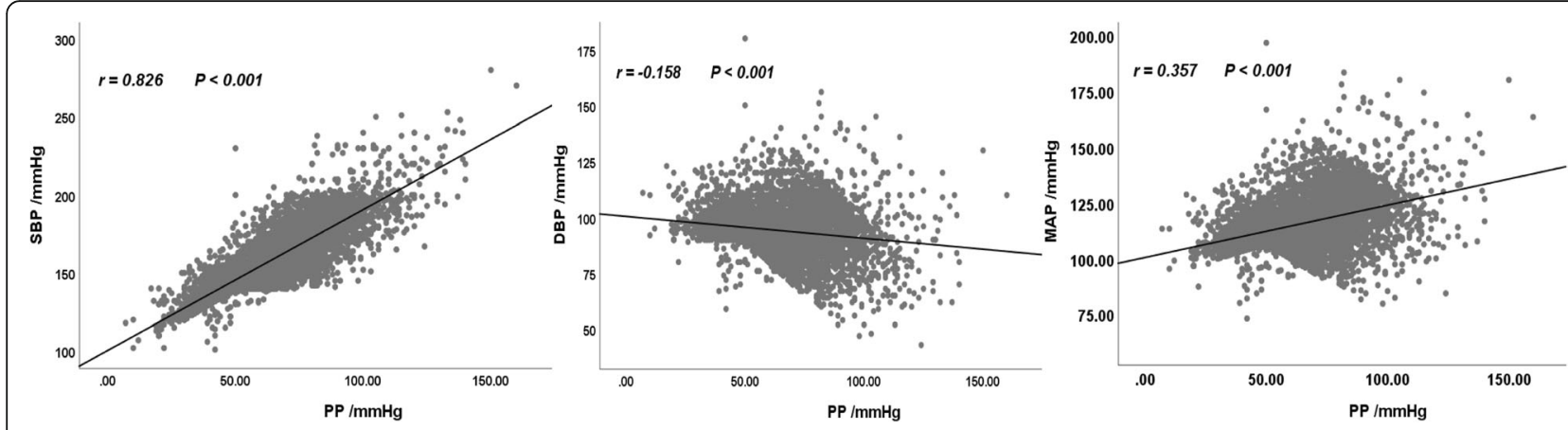

Fig. 2 Scatter plot among the blood pressure parameters

value of $\mathrm{HR}$ for PP among hypertensive subjects aged less than 60 revealed slightly lower than that of SBP for all stroke incident [HR (95\% CI): 1.635 (1.451-1.842) vs 1.734 (1.562-1.9)] and HS incident [HR (95\% CI): 1.788 (1.490$2.145)$ vs $2.053(1.757-2.398)]$. However, the HR value of PP (1.531, 95\% CI: 1.308-1.793, $P<0.001)$ was the highest among the four BP for IS events. The HR values of PP among hypertensive subjects aged over 60 showed the lowest for all stroke (1.228, 95\% CI: $1.86-1.389, P=0.001)$, IS (1.244, 95\% CI: $1.066-1.451, P=0.005)$, and HS (1.200, 95\% CI: $0.972-1481, P=0.090$ ) events.

Table 4 summarizes the results of the predictive power between the four BP parameters for all stroke, IS, and HS. For all stroke, SBP indicated the largest coefficient and PP was lower than SBP, and the difference between SBP and $\mathrm{PP}$ were statistically significant $\left(\beta_{\mathrm{SBP}}=0.435>\beta_{\mathrm{MAP}}=\right.$ $0.430>\beta_{\mathrm{PP}}=0.351>\beta_{\mathrm{DBP}}=0.322$ ). Although the coefficient of MAP was lower than SBP marginally, the difference between MAP and SBP were not statistically significant $(P=$ 0.756). Identical results were observed in the IS and HS events.

\section{Discussion}

The present study provided an in-depth analysis of associations between blood pressure parameters and stroke among rural Chinese persons with hypertension. The results indicated that all the BP parameters were associated with the outcomes, significantly. The study results revealed that SBP was a more effective predictor of the outcomes than DBP and PP excluding MAP.

The increase of PP enhances arteries to bear more stress, which leads to the increase of elastic component fatigue and fracture rate and weaken the lining of blood vessels. Current studies have shown that PP's ability to predict adverse cardiovascular events were controversial $[7,8,11-21]$. Framingham Heart Study had indicated that PP was still a predictor for stroke incident after adjusted by SBP and DBP, even though its predictive ability was inferior to SBP and DBP. Another study had showed that PP was a powerful predictor of stroke incident when DBP and MAP were adjusted, but not when SBP was adjusted [13]. The present study (based on hypertensive patients) showed that the four BP parameters were independent risk factors for stroke after adjusting some acknowledged influential factors of stroke. However, when SBP and DBP were incorporated into the original regulatory factors, the effect of MAP and PP disappeared. The present results doesn't agree with previous study that PP was an independent risk predictor of stroke in the general population [8].

Table 2 Adjusted Hazard Ratios (HRs) of the four BP Parameters for stroke ${ }^{a}$

\begin{tabular}{|c|c|c|c|c|c|c|}
\hline \multirow{2}{*}{$\begin{array}{l}\text { BP } \\
\text { Parameters } \\
\text { (per } 1 \mathrm{SD} \\
\text { mmHg } \\
\text { increased) }\end{array}$} & \multicolumn{2}{|l|}{ All stroke } & \multicolumn{2}{|l|}{ Ischemic Stroke } & \multicolumn{2}{|l|}{ Hemorrhage stroke } \\
\hline & HRs $(95 \% \mathrm{Cl})$ & $P$ & HRs $(95 \% \mathrm{Cl})$ & $P$ & HRs $(95 \%$ Cl) & $P$ \\
\hline SBP & 1.751 (1.589-1.930) & $<0.001$ & 1.619 (1.426-1.839) & $<0.001$ & $2.008(1.721-2.343)$ & $<0.001$ \\
\hline DBP & $1.377(1.302-1.455)$ & $<0.001$ & $1.316(1.224-1.415)$ & $<0.001$ & $1.488(1.363-1.625)$ & $<0.001$ \\
\hline PP & $1.420(1.299-1.552)$ & $<0.001$ & $1.371(1.224-1.537)$ & $<0.001$ & $1.515(1.311-1.750)$ & $<0.001$ \\
\hline MAP & $1.537(1.426-1.656)$ & $<0.001$ & $1.448(1.313-1.596)$ & $<0.001$ & $1.707(1.517-1.922)$ & $<0.001$ \\
\hline
\end{tabular}

$B P$ blood pressure, $S B P$ systolic blood pressure, $D B P$ diastolic blood pressure, $P P$ pulse pressure, $M A P$ mean arterial pressure, $B M I$ body mass index, $H R$ heart rate, $T C$ total cholesterol, $T G$ triglycerides, $H D L-C$ high-density lipoprotein cholesterol, $L D L-C$ low-density lipoprotein cholesterol

${ }^{a}$ Included variables: age (years), sex, ethnicity, BMI, HR, current smoking, current drinking, diabetes mellitus, and anti-hypertension drug treatment, TC, TG, HDL-C, LDL-C 
Table 3 Adjusted Hazard Ratios (HRs) of BP parameters for stroke according to age categories*

\begin{tabular}{|c|c|c|c|c|}
\hline \multirow{2}{*}{$\begin{array}{l}\mathrm{BP} \\
\text { parameters }\end{array}$} & \multicolumn{2}{|l|}{$<60$ years $(n=3250)$} & \multicolumn{2}{|l|}{$\geq 60$ years $(n=1847)$} \\
\hline & HRs $(95 \% \mathrm{Cl})$ & $P$ & HRs $(95 \% \mathrm{Cl})$ & $P$ \\
\hline \multicolumn{5}{|l|}{ All stroke } \\
\hline SBP & $1.734(1.562-1.924)$ & $<0.001$ & $1.360(1.216-1.522)$ & $<0.001$ \\
\hline DBP & $1.442(1.288-1.616)$ & $<0.001$ & $1.304(1.150-1.479)$ & $<0.001$ \\
\hline PP & $1.635(1.451-1.842)$ & $<0.001$ & $1.228(1.086-1.389)$ & 0.001 \\
\hline MAP & $1.696(1.534-1.874)$ & $<0.001$ & $1.337(1.234-1.538)$ & $<0.001$ \\
\hline
\end{tabular}

Ischemic Stroke

$\begin{array}{lllll}\text { SBP } & 1.524(1.322-1.756) & <0.001 & 1.377(1.198-1.582) & <0.001 \\ \text { DBP } & 1.224(1.041-1.439) & 0.014 & 1.315(1.125-1.537) & 0.001 \\ \text { PP } & 1.531(1.308-1.793) & <0.001 & 1.244(1.066-1.451) & 0.005 \\ \text { MAP } & 1.482(1.289-1.703) & <0.001 & 1.392(1.215-1.595) & <0.001\end{array}$

Hemorrhage stroke

$\begin{array}{lllll}\text { SBP } & 2.053(1.757-2.398) & <0.001 & 1.328(1.094-1.613) & 0.004 \\ \text { DBP } & 1.694(1.457-1.970) & <0.001 & 1.280(1.032-1.586) & 0.024 \\ \text { PP } & 1.788(1.490-2.145) & <0.001 & 1.200(0.972-1.481) & 0.090 \\ \text { MAP } & 2.003(1.730-2.320) & <0.001 & 1.348(1.113-1.632) & 0.002\end{array}$

Using the Cox proportional hazards model to calculate the Hazard Ratios of four BP parameters that was standardized for the risk of stroke incident. Adjusted variables: age (years), sex, ethnicity, BMI, HR, current smoking, current drinking, diabetes mellitus, anti-hypertension drug treatment, TC, TG, HDL-C, LDL-C

$B P$ blood pressure, SBP systolic blood pressure, DBP diastolic blood pressure, $P P$ pulse pressure, $M A P$ mean arterial pressure, $B M I$ body mass index, $H R$ heart rate, $T C$ total cholesterol, TG triglycerides, $H D L-C$ high-density lipoprotein cholesterol, LDL-C low-density lipoprotein cholesterol

To eliminate the impact of multiple collinearities among the four BP parameters, the four BP parameters were incorporated into the model to calculate the corresponding coefficient difference. For stroke and its two subtypes (IS and HS), SBP obtained the highest HRs value, which was followed by MAP while the HRs value of PP was lower than the above two and higher than DBP. The comparison results of stroke prediction capacity showed that the prediction ability of SBP was significantly higher than that of DBP and $\mathrm{PP}$, and no significant differences were observed with MAP. The above results suggested that MAP was a sensitive indicator of onset stroke events in hypertensive patients.

It has been observed that $\mathrm{BP}$ (DBP and SBP) increasing in a parallel manner until age $\leq 60$, as age over 60 years, SBP continues to rise, but DBP begins to decrease as a result of reducing revers capacity of aorta with advancing age $[22,27]$. Therefore, PP may be regarded as a powerful indicators of BP for the elderly [8]. The Framingham heart study indicated that the risk of CHD increased by $23 \%$ when PP increasing in every $10 \mathrm{mmHg}$ [13]. This association between CHD risk and PP was observed in patients over 50 years old, especially those over 60 years old [14]. Therefore, the age stratification analysis was carried out in our study with the cut-off value of 60 years old (Table 3). The current study result could not verify that PP was more
Table 4 Comparisons of a Predictive Power between the four BP Parameters for stroke

\begin{tabular}{|c|c|c|}
\hline BP parameters & $\beta$ coefficient & $P$ \\
\hline \multicolumn{3}{|l|}{ All stroke } \\
\hline SBP vs DBP & 0.435 vs 0.322 & $<0.001$ \\
\hline SBP vs PP & 0.435 vs 0.351 & $<0.001$ \\
\hline SBP vs MAP & 0.435 vs 0.430 & 0.756 \\
\hline DBP vs PP & 0.322 vs 0.351 & 0.099 \\
\hline DBP vs MAP & 0.322 vs 0.430 & $<0.001$ \\
\hline PP vs MAP & 0.351 vs 0.430 & $<0.001$ \\
\hline \multicolumn{3}{|l|}{ Ischemic Stroke } \\
\hline SBP vs DBP & 0.378 vs 0.255 & $<0.001$ \\
\hline SBP vs PP & 0.378 vs 0.316 & $<0.001$ \\
\hline SBP vs MAP & 0.378 vs 0.370 & 0.639 \\
\hline DBP vs PP & 0.255 vs 0.316 & $<0.001$ \\
\hline DBP vs MAP & 0.255 vs 0.370 & $<0.001$ \\
\hline PP vs MAP & 0.316 vs 0.370 & 0.002 \\
\hline \multicolumn{3}{|c|}{ Hemorrhage stroke } \\
\hline SBP vs DBP & 0.539 vs 0.425 & $<0.001$ \\
\hline SBP vs PP & 0.539 vs 0.415 & $<0.001$ \\
\hline SBP vs MAP & 0.539 vs 0.535 & 0.777 \\
\hline DBP vs PP & 0.425 vs 0.415 & 0.540 \\
\hline DBP vs MAP & 0.425 vs 0.535 & $<0.001$ \\
\hline PP vs MAP & 0.415 vs 0.535 & $<0.001$ \\
\hline
\end{tabular}

Using the Cox proportional hazards model to calculate the $\beta$-coefficient of four BP parameters that was standardized for the risk of stroke incident. Adjusted variables: age (years), sex, ethnicity, BMI, HR, current smoking, current drinking, diabetes mellitus, and anti-hypertension drug treatment, TC, TG, HDL-C, LDL-C $B P$ blood pressure, SBP systolic blood pressure, DBP diastolic blood pressure, $P P$ pulse pressure, $M A P$ mean arterial pressure, $B M I$ body mass index, $H R$ heart rate, $T C$ total cholesterol, TG triglycerides, HDL-C high-density lipoprotein cholesterol, LDL-C low-density lipoprotein cholesterol

applicable to the elderly population for stroke incident, however, the outcome revealed a high predictive power for the relatively low age group in hypertensive patients.

The main adverse manifestations of stroke are IS and HS, and their incidence increasing with age [28]. As people's life expectancy increases, the burden of stroke on people and society worldwide will become heavier. $75 \%$ of stroke patients were measured to had a high BP at the time of admission [29]. Hypertension-related stroke is a pervasive, on the other hand its preventable public health related problem. Hypertension has been shown to be the most common and the most influential risk factor for IS and HS, and the incidence of IS and HS could be significantly reduced by effective hypertensive therapy $[30,31]$. It is particularly crucial to control $\mathrm{BP}$ and to use sensitive BP parameters. Both PP and MAP were calculated from the main components of BP (SBP and DBP). PP mainly reflects two aspects of ventricular ejection volume and wave reflection [13, 32]. In addition to 
reflecting ventricular ejection and peripheral vascular resistance, MAP was considered as the main determinant of cerebral blood flow [13, 32], which was critical for brain tissue damage [33]. This may be the reason that MAP could predict stroke better than PP and this finding corporate the previous result [34].

\section{Limitation}

Some critical limitations need to be considered. Firstly, the present cohort study was composed of adults who were completely from rural areas in China, and their diversity may be limited. Secondly, in this study only baseline BP values was used, it should be taken into account that stroke vascular damage is a dynamic and complex process over time. Further study are required to the relationship between dynamic BP parameters levels and stroke and to clarify its pathogenesis.

\section{Conclusion}

Within the limitation of the current study, the following conclusion can be drawn. The SBP was supported as the main indicator of BP parameters in predicting stroke risk in hypertensive patients. Although PP could predict stroke risk in hypertensive patients, its predictive ability was lower than SBP. However, the assessment and management of MAP could be considered in clinical BP control and reducing the risk of stroke.

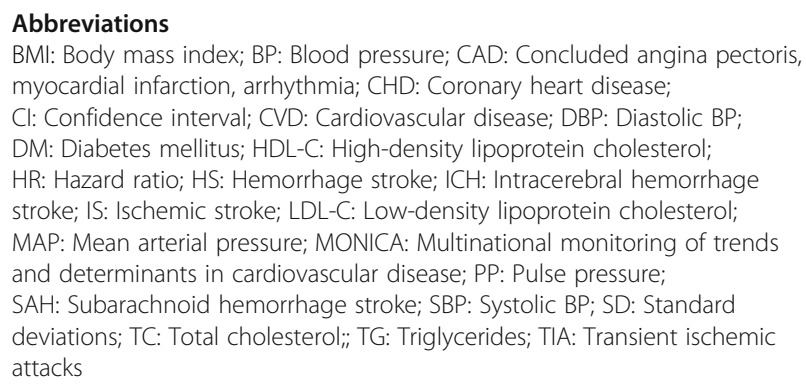

\section{Acknowledgments}

Not applicable.

\section{Authors' contributions}

YS contributed conception and design of the study; JZ, ZS, LZ, XG, GS, and YX organized the database; JZ conducted statistical analysis and wrote the first draft of the manuscript. LZ and ZJ contributed to manuscript revision. All authors have read and approved the submitted version.

\section{Funding}

This work was supported by the National Nature Science Foundation of China [No. 81773510]; National Key R\&D Program of China [Grant \#2017YFC1307600]. All the funding bodies had influence on designing research, data collection, data analyzing, and writing the manuscript.

\section{Availability of data and materials}

The datasets used and/or analyzed during the current study are available from the corresponding author on reasonable request.

\section{Ethics approval and consent to participate}

The China Medical University Ethics Committee had approved the study plan and received the written informed consent from all patients or their guardians.

\section{Consent for publication}

Not applicable.

\section{Competing interests}

The authors declare that they have no competing interests.

\section{Author details}

'Department of Clinical Epidemiology, Library, Department of Health Policy and Hospital Management, Shengjing Hospital of China Medical University, Shenyang 110004, People's Republic of China. ${ }^{2}$ Department of Cardiology, Shengjing Hospital of China Medical University, Shenyang 110004, People's Republic of China. ${ }^{3}$ Department of Cardiology, the First Affiliated Hospital of China Medical University, Shenyang 110001, People's Republic of China.

Received: 11 December 2018 Accepted: 16 August 2019

Published online: 29 August 2019

\section{References}

1. Top 10 causes of death worldwide. 2018. http://www.who.int/mediacentre/ factsheets/fs310/zh/. Accessed 25 Sept 2018.

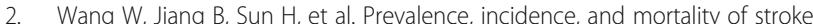
in China: results from a Nationwide population-based survey of 480687 adults. Circulation. 2017;135(8):759-71.

3. Yang G, Wang Y, Zeng Y, Gao GF, Liang X, Zhou M, et al. Rapid health transition in China, 1990-2010: findings from the global burden of disease study 2010. Lancet. 2013;381(9882):1987-2015.

4. Wang Z, Chen Z, Zhang L, Wang X, Hao G, Zhang Z, et al. Status of hypertension in China: results from the China hypertension survey, 20122015. Circulation. 2018;137(22):2344-56.

5. Kelly TN, Gu D, Chen J, et al. Hypertension subtype and risk of cardiovascular disease in Chinese adults. Circulation. 2008;118(15):1558-66.

6. Miura $\mathrm{K}$, Nakagawa $\mathrm{H}$, Ohashi $Y$, et al. Four blood pressure indexes and the risk of stroke and myocardial infarction in Japanese men and women: a meta-analysis of 16 cohort studies. Circulation. 2009;119(14):1892-8.

7. Sabayan B, van Vliet P, de Ruijter W, Gussekloo J, de Craen AJ, Westendorp RG. High blood pressure, physical and cognitive function, and risk of stroke in the oldest old: the Leiden 85-plus study. Stroke. 2013;44(1):15-20.

8. Glasser SP, Halberg DL, Sands CD, Mosher A, Muntner PM, Howard G. Is pulse pressure an independent risk factor for incident stroke, REasons for geographic and racial differences in stroke. Am J Hypertens. 2015;28(8):987-94.

9. de Simone G, Roman MJ, Alderman MH, Galderisi M, de Divitiis O, Devereux RB. Is high pulse pressure a marker of preclinical cardiovascular disease? Hypertension. 2005:45(4):575-9.

10. Verdecchia P, Schillaci G, Reboldi G, Franklin SS, Porcellati C. Different prognostic impact of 24-hour mean blood pressure and pulse pressure on stroke and coronary artery disease in essential hypertension. Circulation. 2001;103(21):2579-84.

11. Li Z, Bai Y, Guo X, Zheng L, Sun Y, Roselle AM. Alcohol consumption and cardiovascular diseases in rural China. Int J Cardiol. 2016;215:257-62.

12. Pastor-Barriuso R, Banegas JR, Damian J, Appel L, Guallar E. Systolic blood pressure, diastolic blood pressure, and pulse pressure: an evaluation of their joint effect on mortality. Ann Intern Med. 2003;139(9):731-9.

13. Franklin SS, Khan SA, Wong ND, Larson MG, Levy D. Is pulse pressure useful in predicting risk for coronary heart disease? The Framingham heart study. Circulation. 1999;100(4):354-60.

14. Franklin SS, Larson MG, Khan SA, Wong ND, Leip EP, Kannel WB, et al. Does the relation of blood pressure to coronary heart disease risk change with aging? The Framingham Heart Study. Circulation. 2001;103(9):1245-9.

15. Thomas F, Blacher J, Benetos A, Safar ME, Pannier B. Cardiovascular risk as defined in the 2003 European blood pressure classification: the assessment of an additional predictive value of pulse pressure on mortality. J Hypertens. 2008;26(6):1072-7

16. Domanski M, Mitchell G, Pfeffer M, Neaton JD, Norman J, Svendsen K, et al. Pulse pressure and cardiovascular disease-related mortality: followup study of the multiple risk factor intervention trial (MRFIT). Jama. 2002;287(20):2677-83 
17. Franklin SS, Lopez VA, Wong ND, Mitchell GF, Larson MG, Vasan RS, et al. Single versus combined blood pressure components and risk for cardiovascular disease: the Framingham heart study. Circulation. 2009;119(2):243-50.

18. Lorenzo C, Aung K, Stern MP, Haffner SM. Pulse pressure, prehypertension, and mortality: the San Antonio heart study. Am J Hypertens. 2009;22(11):1219-26.

19. Okada K, Iso H, Cui R, Inoue M, Tsugane S. Pulse pressure is an independent risk factor for stroke among middle-aged Japanese with normal systolic blood pressure: the JPHC study. J Hypertens. 2011;29(2):319-24.

20. Panagiotakos DB, Kromhout D, Menotti A, Chrysohoou C, Dontas A, Pitsavos $C$, et al. The relation between pulse pressure and cardiovascular mortality in 12,763 middle-aged men from various parts of the world: a 25-year followup of the seven countries study. Arch Intern Med. 2005;165(18):2142-7.

21. Assmann G, Cullen P, Evers T, Petzinna D, Schulte H. Importance of arterial pulse pressure as a predictor of coronary heart disease risk in PROCAM. Eur Heart J. 2005:26(20):2120-6.

22. Franklin SS, Gustin W 4th, Wong ND, Larson MG, Weber MA, Kannel WB, et al. Hemodynamic patterns of age-related changes in blood pressure. The Framingham heart study. Circulation. 1997;96:308-15.

23. Zheng L, Sun Z, Li J, Zhang R, Zhang X, Liu S, et al. Pulse pressure and mean arterial pressure in relation to ischemic stroke among patients with uncontrolled hypertension in rural areas of China. Stroke. 2008;39(7):1932-7.

24. Zheng J, Sun Z, Zhang X, Li Z, Guo X, Xie Y, et al. Non-traditional lipid profiles associated with ischemic stroke not hemorrhagic stroke in hypertensive patients: results from an 8.4 years follow-up study. Lipids Health Dis. 2019;18:1-9.

25. Zhao D, Liu J, Wang W, Zeng Z, Cheng J, Liu J, et al. Epidemiological transition of stroke in China: twenty-one-year observational study from the Sino-MONICA-Beijing project. Stroke. 2008;39(6):1668-74.

26. Zheng L, Sun Z, Zhang X, Li J, Hu D, Sun Y. The association between glomerular filtration rate and stroke in hypertensive patients in rural areas of China. J Hypertens. 2012;30(5):901-7.

27. Messerli FH, Sundgaard-Riise K, Ventura HO, Dunn FG, Glade LB, Frohlich ED. Essential hypertension in the elderly: haemodynamics, intravascular volume, plasma renin activity, and circulating catecholamine levels. Lancet. 1983; 2(8357):983-6.

28. Mozaffarian D, Benjamin EJ, Go AS, Arnett DK, Blaha MJ, Cushman M, et al. Heart disease and stroke statistics--2015 update: a report from the American Heart Association. Circulation. 2015;131(4):e29-322.

29. Qureshi Al, Ezzeddine MA, Nasar A, Suri MF, Kirmani JF, Hussein HM, et al. Prevalence of elevated blood pressure in 563,704 adult patients with stroke presenting to the ED in the United States. Am J Emerg Med. 2007;25(1):32-8.

30. Vaccarino V, Berger AK, Abramson J, Black HR, Setaro JF, Davey JA, et al. Pulse pressure and risk of cardiovascular events in the systolic hypertension in the elderly program. Am J Cardiol. 2001;88(9):980-6.

31. Staessen JA, Thijs L, O'Brien ET, Bulpitt CJ, de Leeuw PW, Fagard RH, et al. Ambulatory pulse pressure as predictor of outcome in older patients with systolic hypertension. Am J Hypertens. 2002;15:835-43.

32. Nichols WW, Nicolini FA, Pepine CJ. Determinants of isolated systolic hypertension in the elderly. J Hypertens Suppl. 1992;10(6):S73-7.

33. Willie CK, Tzeng YC, Fisher JA, Ainslie PN. Integrative regulation of human brain blood flow. J Physiol. 2014;592(5):841-59.

34. Millar JA, Lever AF, Burke V. Pulse pressure as a risk factor for cardiovascular events in the MRC mild hypertension trial. J Hypertens. 1999;17(8):1065-72.

\section{Publisher's Note}

Springer Nature remains neutral with regard to jurisdictional claims in published maps and institutional affiliations.

Ready to submit your research? Choose BMC and benefit from:
- fast, convenient online submission
- thorough peer review by experienced researchers in your field
- rapid publication on acceptance
- support for research data, including large and complex data types
- gold Open Access which fosters wider collaboration and increased citations
- maximum visibility for your research: over 100M website views per year
At BMC, research is always in progress.
Learn more biomedcentral.com/submissions

